\title{
SEVERIDADE DE DOENÇAS EM MARACUJAZEIRO PARA IDENTIFICAÇÃO DE FONTES DE RESISTÊNCIA EM CONDIÇÕES DE CAMPO ${ }^{1}$
}

\author{
EDER JORGE DE OLIVEIRA ${ }^{2}$, TALIANE LEILA SOARES ${ }^{3}$, CRISTIANE DE JESUS BARBOSA ${ }^{4}$, \\ HERMES PEIXOTO SANTOS-FILHO ${ }^{5}$, ONILDO NUNES DE JESUS ${ }^{6}$
}

RESUMO - O objetivo deste trabalho foi utilizar uma escala de severidade para algumas doenças do maracujazeiro, visando à identificação de fontes de resistência. Foram avaliados 75 acessos de Passiflora spp. em condições de campo, sob alta infecção natural dos patógenos, para a severidade da virose, nas folhas (VIFO), frutos (VIFR) e distribuição na planta (VIPL), bem como para verrugose nos frutos e ramos (VEFR e VERA, respectivamente) e antracnose nos frutos (ANFR). Houve alta variabilidade para resistência às doenças, embora poucos acessos tenham sido classificados como resistentes à VIFO, VIFR e VIPL, sendo que apenas um acesso de $P$. setacea (BGM237) foi considerado resistente aos três tipos de avaliações para virose. A maioria dos acessos de maracujazeiro- amarelo e roxo possui algum grau de suscetibilidade a um ou outro sintoma da virose. Quanto à VERA, acessos de P. alata e P. cincinnata foram mais resistentes, embora $P$. alata demonstre maior resistência a VEFR. Alguns acessos de $P$. edulis comportam-se como moderadamente resistente à VERA e VEFR. A maioria dos acessos de $P$. alata, $P$. cincinnata e $P$. setacea não apresentou sintomas de antracnose nos frutos. A escala de severidade adotada mostrou-se eficiente para a separação dos acessos de maracujazeiro em diferentes classes de resistência a doenças.

Termos para indexação: Passiflora; melhoramento genético, resistência genética e variabilidade genética.

\section{DISEASE SEVERITY FROM PASSION FRUIT TO IDENTIFY SOURCES OF RESISTANCE IN FIELD CONDITIONS}

\begin{abstract}
The objective of this study was to use a severity scale for some passion fruit diseases, in order to identify sources of resistance. Seventy-five accessions of Passiflora spp. were evaluated under field conditions and high natural infection of pathogens. Symptoms of virus severity in the leaves (VILE), fruits (VIFR) and distribution in the plant (VIPL), as well as scab on fruit and branches (SCFR and SCBR, respectively) and anthracnose in fruits (ANFR), were analyzed. High variability for disease resistance was observed, although few accessions were classified as resistant to VILE, VIFR and VIPL. Only BGM237 ( $P$. setacea) was considered resistant of these three types of virus evaluation. The most of yellow and purple passion fruit accessions showed some degree of susceptibility to one or another virus symptom. $P$. alata and $P$. cincinnata were more resistant to SCBR, although $P$. alata showed more resistance to SCFR. Some accessions of $P$. edulis were moderately resistant to SCFR and SCBR. The majority of $P$. alata, P. cincinnata and $P$. setacea accessions do not showed symptoms of anthracnose in the fruits. The severity scale proposed was useful to separate the accessions of passion fruit in different classes of disease resistance.
\end{abstract}

Index terms: Passiflora; breeding, genetic resistance, genetic variability.

\footnotetext{
1.(Trabalho 134-12). Recebido em: 10-04-2012. Aceito para publicação em: 01-04-2013.

${ }^{2}$ Dr. Pesquisador da Embrapa Mandioca e Fruticultura, Rua da Embrapa, s/n, Caixa Postal 007, 44380-000 Cruz das Almas (BA). E-mail: eder.oliveira@embrapa.br

${ }^{3}$ Bolsista PNPD/CAPES, Universidade Federal do Recôncavo da Bahia, Campus Universitário de Cruz das Almas, $44380-000$ Cruz das Almas (BA). E-mail: cristiane.barbosa@embrapa.br

${ }^{4}$ Dra. Pesquisadora da Embrapa Mandioca e Fruticultura, Rua da Embrapa, s/n, Caixa Postal 007, 44380-000 Cruz das Almas (BA). E-mail: barbosa@cnpmf.embrapa.br

${ }^{5}$ Dr. Pesquisador da Embrapa Mandioca e Fruticultura, Rua da Embrapa, s/n, Caixa Postal 007, 44380-000 Cruz das Almas (BA). E-mail: hermes.santos@embrapa.br

${ }^{6}$ Dr. Pesquisador da Embrapa Mandioca e Fruticultura, Rua da Embrapa, s/n, Caixa Postal 007, 44380-000 Cruz das Almas (BA). E-mail: onildo.nunes@embrapa.br
} 


\section{INTRODUÇÃO}

As principais espécies de maracujazeiro utilizadas comercialmente são a Passiflora edulis Sims f. flavicarpa Degener (casca roxa e amarela). e a Passiflora alata Curtis (maracujazeiro-doce). Atualmente, o Brasil destaca-se como maior produtor mundial de maracujá, com produção estimada de 920 mil toneladas, produzidas em 62 mil hectares, e $76 \%$ da produção representada pela região Nordeste. Neste cenário, o Estado da Bahia ocupa posição de liderança, sendo responsável por $52 \%$ da área plantada e $50 \%$ da produção brasileira (IBGE, 2010). Cerca de $95 \%$ desta produção é oriunda do maracujazeiro-azedo.

Apesar da sua ampla importância econômica, existem diversos problemas fitossanitários que comprometem a produtividade do maracujazeiro no Brasil (MELETTI, 2011). Dentre as principais doenças da cultura, pode-se destacar as de origem fúngica, como antracnose (Colletotrichum gloeosporioides Penz.), verrugose ou cladosporiose (Cladosporium herbarum Link), fusariose (Fusarium oxysporum f. sp. passiflorae Gordon apud Purss.), manchaparda e a septoriose (Septoria passiflorae Sydow); a bacteriose causada por Xanthomonas axonopodis pv. passiflorae e as de natureza virótica, que causam o endurecimento dos frutos, cuja etiologia, no Brasil, é atribuída ao Passionfruit woodiness virus (PWV) e Cowpea aphid-borne mosaic virus (CABMV) (VAN REGENMORTEL et al., 2000, NASCIMENTO et al., 2004).

A grande suscetibilidade da maioria das variedades de maracujazeiro tem levado a redução da área plantada. Dessa forma, programas de melhoramento têm-se concentrado não somente em obter variedades com características agronômicas desejáveis, mas também resistentes às principais doenças. Como o Brasil é considerado o centro de origem de Passiflora, a busca por fontes de resistência para uso no melhoramento é maximizada em virtude de sua ampla variabilidade genética.

A quantificação de doenças pode ser estimada principalmente pela incidência e severidade (LARANJEIRA et al., 2005). A avaliação da incidência é mais fácil, precisa e simples, já a avaliação da severidade exige a adoção de chaves descritivas, escalas diagramáticas ou a análise de imagens digitalizadas por programas computacionais. Entretanto, a avaliação para resistência a doenças nos programas de melhoramento genético deve utilizar métodos que permitam a obtenção de resultados de forma rápida $\mathrm{e}$ confiável. Por outro lado, o grande número de acessos de germoplasma e de populações segregantes geradas pelo melhoramento dificulta a obtenção de respostas em curto prazo, para direcionar cruzamentos e dirigir a seleção.

No caso do maracujazeiro, existem relatos sobre o uso de escalas descritivas (FISCHER et al., 2009) que apresentam limitações por serem subjetivas e não permitirem um ajuste da acuidade visual na avaliação dos níveis de severidade. Para minimizar a subjetividade das estimativas de severidade entre os avaliadores, escalas diagramáticas tornam-se úteis para quantificar doenças, pois os resultados são reprodutíveis, e a avaliação torna-se mais precisa e acurada (AQUINO et al., 2008; LENZ et al., 2009; CHAGAS et al., 2010).

Considerando-se a escassez de métodos padronizados para quantificar a severidade das principais doenças do maracujazeiro em condições de campo, objetivou-se neste trabalho utilizar uma escala de notas para avaliação da severidade da antracnose, verrugose e endurecimento dos frutos do maracujazeiro, em espécies de Passiflora, sob ocorrência de infestação natural a campo, visando à identificação de fontes de resistência.

\section{MATERIAL E MÉTODOS}

O experimento foi conduzido no campo experimental da Embrapa Mandioca e Fruticultura, localizado em Cruz das Almas-BA, no período de abril a julho de 2009, meses de maior ocorrência de doenças no Recôncavo da Bahia. Setenta e cinco acessos, pertencentes a quatro espécies, sendo 57 de Passiflora edulis Sims. (13 de maracujazeiro- roxo e 44 de maracujazeiro-amarelo), oito de $P$. cincinnata, seis de $P$. alata e quatro de $P$. setacea foram avaliados para a resistência à antracnose, verrugose e endurecimento dos frutos do maracujazeiro. O delineamento experimental utilizado foi de blocos aumentados, com quatro repetições e parcela de dez plantas. Os tratamentos não comuns foram constituídos por 71 acessos, e os tratamentos, comuns por quatro seleções de maracujazeiro- amarelo (A17, B20, J20 e M17) e uma variedade comercial (BRS Gigante Amarelo - BRS GA).

O espaçamento utilizado foi de $2,6 \mathrm{~m}$ entre linhas e de 3,7 m entre plantas. Utilizou-se o sistema de condução em espaldeira vertical, com um fio de arame liso $\mathrm{n}^{\circ} 12$, a $2 \mathrm{~m}$ de altura do solo. Os tratos culturais foram feitos de acordo com recomendações da cultura.

Os sintomas da virose do endurecimento dos frutos, antracnose e verrugose foram avaliados em 15 frutos, coletados aleatoriamente na parcela e no início do processo de maturação. A severidade 
da verrugose também foi avaliada nos ramos, sendo coletados três ramos jovens nas cinco plantas centrais da parcela. No caso do endurecimento dos frutos, foram realizadas avaliações na quinta folha (a partir da folha mais jovem), de ramos jovens, nas cinco plantas centrais da parcela. Também foi avaliada a distribuição dos sintomas da virose nas cinco plantas centrais da parcela, observando-se a distribuição dos sintomas em toda a área ocupada pela planta. Utilizou-se uma escala de notas para todas estas avaliações, conforme apresentado nas Tabelas 1 e 2.

Com a finalidade de avaliar a severidade da virose nas folhas (VIFO), verrugose nos frutos e ramos (VEFR e VERA, respectivamente) e antracnose nos frutos (ANFR), adotou-se a seguinte escala: 1,00 a 1,50: resistente (R); 1,51 a 2,50: moderadamente resistente (MR); 2,51 a 3,50: suscetível (S), e 3,51 a 4,00: altamente suscetível (AS). Para a reação dos acessos de maracujazeiro quanto à severidade da virose nos frutos (VIFR) e distribuição na planta (VIPL), a seguinte escala: 1,00 a 1,30 resistentes; 1,31 a 1,80: moderadamente suscetível (MS), e acima de 1,81: suscetível. As avaliações foram realizadas por dois avaliadores com experiência na avaliação de doenças do maracujazeiro.

Os dados foram analisados, utilizando estatística não paramétrica. As notas foram transformadas em ranks e analisadas pelo teste de Kruskal-Wallis, ao nível de $5 \%$ de probabilidade. Em seguida, os tratamentos foram comparados pelo teste de Waller-Duncan $(p<0,05)$. Todas estas análises foram realizadas com o uso do pacote "agricolae", implementado no programa R (R DEVELOPMENT CORE TEAM, 2006).

\section{RESULTADOS E DISCUSSÃO}

O teste de Kruskall-Wallis revelou diferenças significativas entre os acessos avaliados para todas as doenças, à exceção da severidade da virose nos frutos (VIFR) (Tabela 3). A maior influência ambiental na expressão dos sintomas da virose nos frutos pode ter contribuído para a não detecção de significância para esta característica, uma vez que se observou variação de notas de 1,00 a 2,20 (Tabela 4). Adicionalmente, existem relatos de variabilidade para esta característica em germoplasma de base genética mais restrita, como progênies de maracujazeiro-amarelo (JUNQUEIRA et al., 2003).

A reação dos acessos de maracujazeiro à severidade das doenças é apresentada na Tabela 4. Com relação à avaliação de VIFO, observou-se grande variabilidade entre e dentro das espécies estudadas. Entretanto, a maioria dos acessos ava- liados $(80 \%)$ apresentou mosaico e enrugamento das folhas, dentre os quais todos os acessos de $P$. alata, três de $P$. cincinnata, 12 de $P$. edulis roxo e 39 de $P$. edulis amarelo. Quarenta e dois acessos foram classificados como MR, embora os acessos BGM275, BGM292, BGM312, BGM322, BGM053, BGM332, BGM334, BGM341, BRS Gigante Amarelo, BGM238, BGM242 e BGM272 tenham apresentado sintomas mais amenos da doença com tendência ao aparecimento de poucos sintomas. Por outro lado, os acessos BGM121 (P. edulis amarelo), BGM342 ( $P$. cincinnata) e BGM237 ( $P$. setaceae) comportaram-se como resistentes à VIFO (Tabela 4).

$\mathrm{O}$ intuito de promover a avaliação de espécie de Passiflora, sobretudo P. cincinnata e P. setácea, deve-se ao fato de que observações de campo indicaram que estas espécies tendem a apresentar sintomas mais leves da virose do endurecimento dos frutos. De fato, Junqueira et al. (2005) avaliaram a resistência das espécies $P$. actinia, $P$. caerulea, $P$. setacea e $P$. coccinea à virose do endurecimento nas folhas $\mathrm{e}$ constataram alto nível de resistência nestas espécies, inclusive nas plantas oriundas do cruzamento destas espécies com P. edulis amarelo. Entretanto, nossos dados indicam que há uma grande variação dentro destas espécies e que a recomendação de uso destas espécies deve levar em consideração a origem do acesso.

A identificação de fontes de resistência a viroses do maracujazeiro constitui-se em uma atividade prioritária nos programas de melhoramento genético, por se tratar de uma doença generalizada nas principais regiões produtoras do Brasil. Assim, a avaliação da resistência à virose em progênies melhoradas de maracujazeiro-amarelo tem sido realizada, embora os resultados demonstrem que, na maioria dos casos, as plantas são classificadas de medianamente resistentes a suscetíveis (LEÃO et al., 2006). No presente trabalho, indicação de resistência em P. edulis amarelo abre novas perspectivas para acelerar o desenvolvimento de variedades resistentes à doença, tendo em vista que não haveria os problemas inerentes ao uso de espécies silvestres muito distantes geneticamente das variedades comerciais.

Embora não tenha sido detectada diferença estatística entre os acessos avaliados para VIFR, verifica-se uma variação nas notas para esta doença de 1,0 a 2,2, sendo considerados, respectivamente como frutos normais, sem deformação e frutos ligeiramente deformados, com ou sem manchas (Tabela 4). Seis acessos de $P$. cincinnata, nove de $P$. edulis roxo, 16 de $P$. edulis amarelo e quatro de $P$. setacea foram considerados resistentes à VIFR. $\mathrm{O}$ acesso BGM121 apresentou nota de 1,60, interme- 
diária à escala de nota de 1 a 3 , enquanto os outros acessos, tidos como resistentes à VIFO (BGM342 e BGM237), não apresentaram deformação nos frutos. Outros três acessos de $P$. cincinnata, cinco de $P$. edulis roxo, cinco de $P$. edulis amarelo e três de $P$. setacea apresentaram o mesmo comportamento, constituindo-se em excelentes fontes de resistência à doença (Tabela 4).

Quanto à distribuição da virose nas plantas de maracujazeiro (VIPL), os acessos BGM322, BGM053, BGM168, BGM216, BGM277, BGM158, BGM237, BGM242 e BGM272, pertencentes às espécies $P$. cincinnata, $P$. edulis roxo, $P$. setacea e $P$. edulis amarelo, foram os mais resistentes (nota 1,00), embora os acessos BGM292, BGM238, BGM140, BGM188 e BGM023 também sejam considerados resistentes (nota 1,20). Por outro lado, o comportamento destes acessos quanto à VIFO pode ser considerado de MS a S, com notas variando de 1,60 a 2,60. Isto indica a presença de certa severidade da virose, embora estejam presentes em poucas folhas, em comparação ao volume de copa apresentado por estes acessos, o que pode indicar constituir- se em mecanismo de resistência à doença. Esta hipótese corrobora as observações para a espécie $P$. setacea (BGM237, BGM242 e BGM272), na qual não se observam sintomas da virose nos frutos e baixa distribuição na planta, embora seja possível observar folhas com mosaico leve e algumas deformações.

Os acessos BGM342, BGM237 e BGM121 apresentaram notas variando de 1,40 a 1,60 para VIPL, o que indica algum grau de tolerância à distribuição da doença na planta. Por outro lado, as testemunhas J20, M17, A17, B20 e BRS Gigante Amarelo apresentaram sintomas mais acentuados da VIFO (variação de 1,86 a 2,22), mais leves para $\operatorname{VIFR}(1,12$ a 1,72$)$ e moderados para VIPL $(1,60$ a 2,00) (Tabela 4).

A reação dos acessos de maracujazeiro à verrugose nos frutos também demonstra a alta variabilidade para a resistência ao patógeno. De modo geral, os acessos de maracujazeiro-amarelo e roxo foram os mais suscetíveis aos sintomas da doença nos frutos. Apenas dois acessos de $P$. setacea (BGM242 e BGM272) apresentaram imunidade ao fungo. Os outros dois acessos desta espécie (BGM237 e BGM238) apresentaram frutos com até $10 \%$ da área coberta por lesões, demonstrando vulnerabilidade ao patógeno, sendo considerados resistentes. Outros três acessos de $P$. alata, três de $P$. cincinnata, seis de $P$. edulis roxo, 16 de $P$. edulis amarelo e um de $P$. setacea foram considerados MR. Dentre estes, os acessos de $P$. alata (BGM235), P. edulis roxo (BGM022 e BGM029) e de P. edulis amarelo
(BGM188 e BGM341) apresentaram a menor severidade à VEFR (notas de 1,60 a 1,80), embora a análise de Waller-Duncan não demonstre diferença estatística entre estes e os demais acessos, com notas até 2,82 (Tabela 4).

Ao analisar cinquenta acessos de maracujazeiro-amarelo em condições de campo, Miranda (2004) observou moderada resistência à verrugose. Resultados similares também foram observados por Abreu (2006), que não encontrou diferenças significativas entre cinco genótipos avaliados em relação à severidade da verrugose nos frutos, apresentando variação de 4,18 a 5,30\% da superfície do fruto coberta com lesões. As inconsistências nestas indicações do grau de resistência do maracujazeiro à verrugose pode ser devido às condições ambientais de análise e mesmo a presença de diferenças na agressividade do patógeno, conforme relatos de Gonçalves (2011).

Os sintomas da verrugose nos ramos foram mais severos nos acessos de maracujazeiro-amarelo e roxo. Entretanto, alguns acessos de $P$. edulis foram considerados resistentes, tais como BGM007, BGM181, BGM205, BGM208, BGM215 e BGM 332 , com notas menores que 1,50. Outra espécie que foi acometida pela alta severidade da verrugose no ramo foi $P$. cincinnata com notas variando de 1,80 a 3,20. Por outro lado, acessos de P. setacea (BGM237) e de P. alata (BGM230, BGM232, BGM162 e BGM163) também se comportaram como resistentes. Cinquenta e cinco acessos foram classificados como $\mathrm{MR}$, e outros nove, como S.

Em relação aos sintomas da antracnose nos frutos (ANFR), os acessos altamente suscetíveis, com notas variando de 3,60 a 3,80, são de $P$. edulis. Outros seis acessos de $P$. edulis roxo e 26 de $P$. edulis amarelo foram classificados como suscetíveis (Tabela 4). Não foram observados sintomas da verrugose nos frutos, nos acessos de $P$. alata (BGM230, BGM232, BGM163, BGM162, BGM004 e BGM235), $P$. cincinnata (BGM268, BGM292 e BGM342), $P$. edulis amarelo (BGM064) e a maioria de $P$. setaceae (BGM237, BGM242, BGM272 e BGM238).

Junqueira et al. (2003) observaram diferenças significativas em progênies de maracujazeiro-amarelo quanto à reação à antracnose nos frutos, porém não foi observado resistência completa. A ausência de resistência completa dentro da espécie $P$. edulis amarela também foi relatada por outros autores (MARTINS, 2006; BOUZA, 2009). O híbrido BRS Gigante Amarelo, utilizado como testemunha, comportou-se como moderadamente resistente à antracnose nos frutos, enquanto as outras testemunhas foram consideradas suscetíveis. Este mesmo comportamento foi relatado por Bouza (2009). 
TABELA 1 - Escala de notas utilizada para avaliação de sintomas do vírus do endurecimento dos frutos nas folhas, frutos e plantas de maracujazeiro, com adaptações de Novaes e Rezende (1999).

\begin{tabular}{cccc}
\hline Notas & \multicolumn{3}{c}{ Sintomatologia visual } \\
\cline { 2 - 4 } 2 & Folhas & Fruto & Planta \\
\hline 2 & $\begin{array}{c}\text { Folha apresentando mosaico leve e } \\
\text { sem deformações foliares }\end{array}$ & $\begin{array}{c}\text { Fruto normal, } \\
\text { sem deformação }\end{array}$ & $\begin{array}{c}\text { Planta pouco infectada, com sintomas } \\
\text { leves de mosaico, com pouco } \\
\text { enrugamento das folhas } \\
\text { com ou sem manchas } \\
\text { Planta medianamente infectada, } \\
\text { com sintomas de mosaico e } \\
\text { enrugamento das folhas }\end{array}$ \\
3 & $\begin{array}{c}\text { Folha apresentando mosaico leve, } \\
\text { bolhas e deformações foliares }\end{array}$ & $\begin{array}{c}\text { Fruto totalmente deformado } \\
\text { com manchas e } \\
\text { forte endurecimento dos frutos }\end{array}$ & $\begin{array}{c}\text { Planta severamente infectada, } \\
\text { com sintomas de mosaico e } \\
\text { enrugamento severo das folhas }\end{array}$ \\
\hline $\begin{array}{c}\text { Folha apresentando mosaico severo, } \\
\text { bolhas e deformações foliares }\end{array}$ & - & - \\
\hline
\end{tabular}

TABELA 2- Escala de notas utilizada para avaliação de sintomas da verrugose e antracnose nos frutos, e verrugose nos ramos de maracujazeiro com adaptações de Junqueira et al. (2003).

\begin{tabular}{cl}
\hline Notas & \multicolumn{1}{c}{ Sintomatologia visual } \\
\hline 1 & Ausência de sintomas \\
2 & Até 10\% da superfície do fruto/ramo coberto com lesões \\
3 & De 11 a 30\% da superfície do fruto/ramo coberto com lesões \\
4 & Acima de 31\% da superfície do fruto/ramo coberto com lesões \\
\hline
\end{tabular}

TABELA 3 - Valores do teste de Kruskal-Wallis para a severidade das doenças do maracujazeiro.

\begin{tabular}{ccc}
\hline Variáveis $^{(1)}$ & Valor do teste & Valor $\mathrm{p}^{(2)}$ \\
\hline VIFO & 1,764 & $0,000^{*}$ \\
VIFR & 1,302 & $0,059 \mathrm{~ns}$ \\
VIPL & 1,551 & $0,000^{*}$ \\
VEFR & 1,472 & $0,000^{*}$ \\
VERA & 1,267 & $0,000^{*}$ \\
ANFR & 2,475 & $0,000^{*}$ \\
\hline
\end{tabular}

(1)VIFO, VIFR e VIPL = severidade da virose nas folhas, frutos e distribuição na planta, respectivamente; VEFR e VERA = severidade da verrugose nos frutos e ramos, respectivamente; ANFR = severidade da antracnose no fruto, ${ }^{(2)}$ probabilidade do erro $(\mathrm{p}<0,05) ; \mathrm{ns}=$ não significativo. * = significativo a 5\% de probabilidade, pelo teste de Kruskal-Wallis.

TABELA 4 - Rank médio da severidade da virose nas folhas (VIFO), frutos (VIFR), distribuição na planta (VIPL), verrugose nos frutos (VEFR) e ramos (VERA) e antracnose nos frutos (ANFR) em 75 acessos de maracujazeiro.

\begin{tabular}{lccccccc}
\hline \multirow{2}{*}{ Acessos } & \multirow{2}{*}{ Espécies $^{1}$} & \multicolumn{7}{c}{ Ranks } \\
\cline { 2 - 7 } A17 & $P e-a$ & 2,2 abcdef & $1,36 \mathrm{a}$ & $1,32 \mathrm{ab}$ & $2,46 \mathrm{abcd}$ & $1,66 \mathrm{ab}$ & 2,54 abcdefg \\
B20 & $P e-a$ & 2,06 abcdef & $1,12 \mathrm{a}$ & $1,36 \mathrm{ab}$ & $2,38 \mathrm{abcd}$ & $1,88 \mathrm{ab}$ & 2,54 abcdefg \\
BGM004 & $P a$ & 2,6 abcdef & $1,8 \mathrm{a}$ & $2,4 \mathrm{ab}$ & $2,0 \mathrm{abcd}$ & $1,8 \mathrm{ab}$ & $1,0 \mathrm{~g}$ \\
BGM007 & $P e-a$ & 2,6 abcdef & $1,8 \mathrm{a}$ & $1,8 \mathrm{ab}$ & $3,4 \mathrm{ab}$ & $1,4 \mathrm{ab}$ & $2,8 \mathrm{abcdef}$ \\
BGM009 & $P e-r$ & 2,6 abcdef & $2,2 \mathrm{a}$ & $1,6 \mathrm{ab}$ & $2,4 \mathrm{abcd}$ & $1,6 \mathrm{ab}$ & 2,2 abcdefg \\
BGM016 & $P c$ & 2,7 abcdef & $1,6 \mathrm{a}$ & $2,0 \mathrm{ab}$ & $3,0 \mathrm{abc}$ & $2,4 \mathrm{ab}$ & $1,8 \mathrm{cdefg}$ \\
BGM017 & $P e-a$ & 2,3 abcdef & $2,0 \mathrm{a}$ & $1,4 \mathrm{ab}$ & $2,0 \mathrm{abcd}$ & $2,2 \mathrm{ab}$ & $3,4 \mathrm{abc}$ \\
BGM022 & $P e-r$ & 2,9 abcde & $1,0 \mathrm{a}$ & $1,6 \mathrm{ab}$ & $1,8 \mathrm{abcd}$ & $1,6 \mathrm{ab}$ & $3,6 \mathrm{ab}$ \\
BGM023 & $P e-r$ & 2,8 abcde & $1,2 \mathrm{a}$ & $1,2 \mathrm{ab}$ & $2,8 \mathrm{abcd}$ & $2,2 \mathrm{ab}$ & 3,0 abcde \\
BGM028 & $P e-a$ & 2,1 abcdef & $1,8 \mathrm{a}$ & $1,8 \mathrm{ab}$ & $2,4 \mathrm{abcd}$ & $2,2 \mathrm{ab}$ & $2,8 \mathrm{abcdef}$ \\
BGM029 & $P e-r$ & 2,4 abcdef & $1,2 \mathrm{a}$ & $1,8 \mathrm{ab}$ & $1,8 \mathrm{abcd}$ & $2,4 \mathrm{ab}$ & 2,4 abcdefg \\
BGM033 & $P e-r$ & 2,7 abcdef & $1,8 \mathrm{a}$ & $1,6 \mathrm{ab}$ & $3,0 \mathrm{abc}$ & $2,2 \mathrm{ab}$ & $3,8 \mathrm{a}$ \\
BGM034 & $P e-a$ & 3,0 abcd & $1,8 \mathrm{a}$ & $2,2 \mathrm{ab}$ & $3,2 \mathrm{abc}$ & $2,4 \mathrm{ab}$ & $3,0 \mathrm{abcde}$ \\
BGM041 & $P e-a$ & $3,3 \mathrm{ab}$ & $1,8 \mathrm{a}$ & $1,6 \mathrm{ab}$ & $2,6 \mathrm{abcd}$ & $2,0 \mathrm{ab}$ & $1,8 \mathrm{cdefg}$ \\
BGM043 & $P e-r$ & 2,6 abcdef & $1,2 \mathrm{a}$ & $1,8 \mathrm{ab}$ & $3,2 \mathrm{abc}$ & $2,2 \mathrm{ab}$ & $3,4 \mathrm{abc}$ \\
BGM044 & $P e-r$ & 2,8 abcde & $1,2 \mathrm{a}$ & $2,0 \mathrm{ab}$ & $2,6 \mathrm{abcd}$ & $2,6 \mathrm{ab}$ & $2,8 \mathrm{abcdef}$ \\
BGM048 & $P e-a$ & 2,9 abcde & $2,0 \mathrm{a}$ & $1,6 \mathrm{ab}$ & $2,8 \mathrm{abcd}$ & $2,4 \mathrm{ab}$ & $2,0 \mathrm{bcdefg}$ \\
BGM049 & $P e-a$ & 2,8 abcde & $1,6 \mathrm{a}$ & $2,2 \mathrm{ab}$ & $3,6 \mathrm{a}$ & $2,2 \mathrm{ab}$ & $2,8 \mathrm{abcdef}$
\end{tabular}




\begin{tabular}{|c|c|c|c|c|c|c|c|}
\hline BGM051 & $P e-a$ & $3,2 \mathrm{ab}$ & $2,2 \mathrm{a}$ & $2,4 \mathrm{ab}$ & 2,8 abcd & $2,0 \mathrm{ab}$ & $3,4 \mathrm{abc}$ \\
\hline BGM053 & $P e-r$ & 1,8 bcdef & $1,0 \mathrm{a}$ & $1,0 \mathrm{~b}$ & $3,2 a b c$ & $2,6 \mathrm{ab}$ & 2,2 abcdefg \\
\hline BGM064 & $P e-a$ & 2,7 abcdef & $1,8 \mathrm{a}$ & $2,4 a b$ & $3,2 \mathrm{abc}$ & $3,2 \mathrm{a}$ & $1,2 \mathrm{fg}$ \\
\hline BGM071 & $P e-a$ & 2,2 abcdef & $1,4 \mathrm{a}$ & $1,4 \mathrm{ab}$ & $2,6 \mathrm{abcd}$ & $2,0 \mathrm{ab}$ & 2,0 bcdefg \\
\hline BGM076 & $P e-r$ & 2,0 abcdef & $1,8 \mathrm{a}$ & $1,8 \mathrm{ab}$ & 2,8 abcd & $2,4 \mathrm{ab}$ & 2,2 abcdefg \\
\hline BGM078 & $P e-a$ & 2,6 abcdef & $2,2 \mathrm{a}$ & $1,6 \mathrm{ab}$ & 2,8 abcd & $1,6 \mathrm{ab}$ & 2,6 abcdefg \\
\hline BGM079 & $P e-a$ & 2,5 abcdef & $1,4 \mathrm{a}$ & $1,4 a b$ & $3,2 a b c$ & $1,6 \mathrm{ab}$ & 3,4 abc \\
\hline BGM092 & $P e-r$ & $3,1 \mathrm{abc}$ & $1,0 \mathrm{a}$ & $2,0 \mathrm{ab}$ & 2,2 abcd & $2,0 \mathrm{ab}$ & $3,4 \mathrm{abc}$ \\
\hline BGM094 & $P e-a$ & 2,7 abcdef & $1,2 \mathrm{a}$ & $2,4 \mathrm{ab}$ & $2,8 \mathrm{abcd}$ & $2,4 \mathrm{ab}$ & 2,2 abcdefg \\
\hline BGM116 & $P e-r$ & 2,8 abcde & $1,0 \mathrm{a}$ & $1,4 a b$ & 2,4 abcd & $2,2 \mathrm{ab}$ & 3,2 abcd \\
\hline BGM121 & $P e-a$ & $1,2 \mathrm{f}$ & $1,6 \mathrm{a}$ & $1,4 a b$ & 2,2 abcd & $2,6 a b$ & 2,6 abcdefg \\
\hline BGM123 & $P e-a$ & 2,2 abcdef & $1,4 \mathrm{a}$ & $1,6 a b$ & $3,0 a b c$ & $2,0 \mathrm{ab}$ & 2,8 abcdef \\
\hline BGM140 & $P e-a$ & 1,9 abcdef & $1,0 \mathrm{a}$ & $1,2 \mathrm{ab}$ & 2,6 abcd & $2,0 \mathrm{ab}$ & 2,8 abcdef \\
\hline BGM158 & $P e-a$ & 2,2 abcdef & $1,6 \mathrm{a}$ & $1,0 \mathrm{~b}$ & 2,6 abcd & $2,6 \mathrm{ab}$ & 2,6 abcdefg \\
\hline BGM162 & $P a$ & 2,8 abcde & $1,8 \mathrm{a}$ & $1,6 \mathrm{ab}$ & $3,0 \mathrm{abc}$ & $1,4 \mathrm{ab}$ & $1,0 \mathrm{~g}$ \\
\hline BGM163 & $\mathrm{Pa}$ & 2,4 abcdef & $1,6 \mathrm{a}$ & $2,0 \mathrm{ab}$ & $3,0 a b c$ & $1,2 \mathrm{~b}$ & $1,0 \mathrm{~g}$ \\
\hline BGM168 & $P e-r$ & 2,1 abcdef & $1,0 \mathrm{a}$ & $1,0 \mathrm{~b}$ & 2,6 abcd & $1,6 a b$ & $1,4 \mathrm{efg}$ \\
\hline BGM181 & $P e-a$ & 2,4 abcdef & $2,2 \mathrm{a}$ & $1,6 a b$ & $3,0 a b c$ & $1,4 a b$ & $3,4 a b c$ \\
\hline BGM185 & $P e-a$ & 2,9 abcde & $1,8 \mathrm{a}$ & $1,6 a b$ & 2,8 abcd & $2,0 \mathrm{ab}$ & 2,8 abcdef \\
\hline BGM186 & $P e-a$ & 2,5 abcdef & $1,2 \mathrm{a}$ & $2,0 \mathrm{ab}$ & 2,6 abcd & $2,8 \mathrm{ab}$ & 3,2 abcd \\
\hline BGM188 & $P e-a$ & 20 , abcdef & $1,2 \mathrm{a}$ & $1,2 \mathrm{ab}$ & $1,6 \mathrm{bcd}$ & $2,0 a b$ & $3,8 \mathrm{a}$ \\
\hline BGM205 & $P e-a$ & 2,6 abcdef & $1,4 \mathrm{a}$ & $1,4 \mathrm{ab}$ & 2,6 abcd & $1,4 a b$ & 2,6 abcdefg \\
\hline BGM208 & $P e-a$ & 2,6 abdef & $1,0 \mathrm{a}$ & $2,2 \mathrm{ab}$ & $2,4 \mathrm{abcd}$ & $1,4 \mathrm{ab}$ & $3,6 \mathrm{ab}$ \\
\hline BGM215 & $P e-a$ & 1,9 abcdef & $1,0 \mathrm{a}$ & $1,4 \mathrm{ab}$ & 2,6 abcd & $1,4 a b$ & 1,4 efg \\
\hline BGM216 & $P e-a$ & 2,6 abcdef & $1,0 \mathrm{a}$ & $1,0 \mathrm{~b}$ & 2,0 abcd & $1,6 a b$ & 2,6 abcdefg \\
\hline BGM222 & $P e-a$ & 2,9 abcde & $2,0 \mathrm{a}$ & $1,6 \mathrm{ab}$ & 2,6 abcd & $1,8 \mathrm{ab}$ & 2,8 abcdef \\
\hline BGM227 & $P e-a$ & 2,9 abcde & $1,2 \mathrm{a}$ & $2,2 \mathrm{ab}$ & 2,2 abcd & $2,4 a b$ & 1,8 cdefg \\
\hline BGM229 & $P e-r$ & 2,8 abcde & $1,4 \mathrm{a}$ & $1,6 \mathrm{ab}$ & $2,4 \mathrm{abcd}$ & $2,8 \mathrm{ab}$ & 3,0 abcde \\
\hline BGM230 & $P a$ & 2,8 abcde & $1,6 \mathrm{a}$ & $2,0 \mathrm{ab}$ & $2,4 \mathrm{abcd}$ & $1,2 \mathrm{~b}$ & $1,0 \mathrm{~g}$ \\
\hline BGM232 & $P a$ & $3,4 \mathrm{a}$ & $1,4 \mathrm{a}$ & $2,6 \mathrm{a}$ & 2,6 abcd & $1,2 \mathrm{~b}$ & $1,0 \mathrm{~g}$ \\
\hline BGM235 & $P a$ & 2,4 abcdef & $1,4 \mathrm{a}$ & $1,8 \mathrm{ab}$ & $1,8 \mathrm{abcd}$ & $1,6 \mathrm{ab}$ & $1,2 \mathrm{fg}$ \\
\hline BGM237 & $P s$ & $1,5 \mathrm{def}$ & $1,0 \mathrm{a}$ & $1,0 \mathrm{~b}$ & $1,4 \mathrm{~cd}$ & $1,2 \mathrm{~b}$ & $1,0 \mathrm{~g}$ \\
\hline BGM238 & $P S$ & $1,6 \mathrm{cdef}$ & $1,0 \mathrm{a}$ & $1,2 \mathrm{ab}$ & $1,6 \mathrm{bcd}$ & $2,4 \mathrm{ab}$ & $1,0 \mathrm{~g}$ \\
\hline BGM242 & Ps & 1,8 bcdef & $1,0 \mathrm{a}$ & $1,0 \mathrm{~b}$ & $1,0 \mathrm{~d}$ & $1,6 a b$ & $1,0 \mathrm{~g}$ \\
\hline BGM268 & $P c$ & 2,0 abcdef & $1,2 \mathrm{a}$ & $2,0 \mathrm{ab}$ & $2,4 \mathrm{abcd}$ & $2,2 \mathrm{ab}$ & $1,0 \mathrm{~g}$ \\
\hline BGM272 & Ps & 1,8 bcdef & $1,0 \mathrm{a}$ & $1,0 \mathrm{~b}$ & $1,0 \mathrm{~d}$ & $2,2 \mathrm{ab}$ & $1,0 \mathrm{~g}$ \\
\hline BGM274 & $P c$ & 2,4 abcdef & $1,0 \mathrm{a}$ & $2,0 \mathrm{ab}$ & $1,4 \mathrm{~cd}$ & $2,0 \mathrm{ab}$ & 1,4 efg \\
\hline BGM275 & $P c$ & 1,6 cdef & $1,4 \mathrm{a}$ & $1,6 a b$ & 2,0 abcd & $2,2 \mathrm{ab}$ & 1,8 cdefg \\
\hline BGM277 & $P e-a$ & 2,4 abcdef & $1,2 \mathrm{a}$ & $1,0 \mathrm{~b}$ & 2,2 abcd & $1,8 \mathrm{ab}$ & 1,8 cdefg \\
\hline BGM292 & $P c$ & $1,6 \mathrm{cdef}$ & $1,0 \mathrm{a}$ & $1,2 \mathrm{ab}$ & $2,8 \mathrm{abcd}$ & $2,2 a b$ & $1,0 \mathrm{~g}$ \\
\hline BGM311 & $P e-a$ & 2,5 abcdef & $1,4 \mathrm{a}$ & $2,6 \mathrm{a}$ & $2,2 \mathrm{abcd}$ & $1,8 \mathrm{ab}$ & 2,6 abcdefg \\
\hline BGM312 & $P c$ & 1,8 bcdef & $1,0 \mathrm{a}$ & $1,4 \mathrm{ab}$ & 2,6 abcd & $1,8 \mathrm{ab}$ & 1,4 efg \\
\hline BGM322 & $P c$ & 1,8 bcdef & $1,2 \mathrm{a}$ & $1,0 \mathrm{~b}$ & 2,6 abcd & $3,2 \mathrm{a}$ & 1,6 defg \\
\hline BRS GA & $P e-a$ & 1,86 bcdef & $1,34 \mathrm{a}$ & $1,62 \mathrm{ab}$ & 2,82 abcd & $1,84 \mathrm{ab}$ & 2,06 abcdefg \\
\hline BGM332 & $P e-a$ & $1,6 \mathrm{cdef}$ & $1,2 \mathrm{a}$ & $1,6 a b$ & 2,6 abcd & $1,4 \mathrm{ab}$ & 2,0 bcdefg \\
\hline BGM333 & $P e-a$ & 2,0 abcdef & $1,0 \mathrm{a}$ & $1,4 \mathrm{ab}$ & $2,4 \mathrm{abcd}$ & $2,0 \mathrm{ab}$ & 2,8 abcdef \\
\hline BGM334 & $P e-a$ & 1,6 cdef & $1,2 \mathrm{a}$ & $1,8 \mathrm{ab}$ & 2,2 abcd & $2,0 \mathrm{ab}$ & 2,6 abcdefg \\
\hline BGM335 & $P e-a$ & 2,4 abcdef & $1,4 \mathrm{a}$ & $1,4 \mathrm{ab}$ & $3,4 \mathrm{ab}$ & $2,4 \mathrm{ab}$ & 3,2 abcd \\
\hline BGM336 & $P e-a$ & 2,6 abcdef & $1,2 \mathrm{a}$ & $1,8 \mathrm{ab}$ & 2,4 abcd & $1,6 \mathrm{ab}$ & 2,2 abcdefg \\
\hline BGM337 & $P e-a$ & 2,2 abcdef & $1,6 \mathrm{a}$ & $1,6 \mathrm{ab}$ & 2,6 abcd & $2,0 \mathrm{ab}$ & 2,0 bcdefg \\
\hline BGM338 & $P e-a$ & 2,4 abcdef & $1,4 \mathrm{a}$ & $1,8 \mathrm{ab}$ & $2,4 \mathrm{abcd}$ & $1,6 \mathrm{ab}$ & 2,0 bcdefg \\
\hline BGM339 & $P e-a$ & 2,2 abcdef & $1,2 \mathrm{a}$ & $2,0 \mathrm{ab}$ & $3,0 \mathrm{abc}$ & $2,0 \mathrm{ab}$ & 2,4 abcdefg \\
\hline BGM340 & $P e-a$ & 2,2 abcdef & $1,6 \mathrm{a}$ & $2,4 \mathrm{ab}$ & 2,6 abcd & $2,0 \mathrm{ab}$ & 2,0 bcdefg \\
\hline BGM341 & $P e-a$ & $1,6 \mathrm{cdef}$ & $1,6 \mathrm{a}$ & $2,4 \mathrm{ab}$ & $1,8 \mathrm{abcd}$ & $2,0 \mathrm{ab}$ & 1,8 cdefg \\
\hline BGM342 & $P c$ & 1,4 ef & $1,0 \mathrm{a}$ & $1,4 \mathrm{ab}$ & 2,2 abcd & $2,6 \mathrm{ab}$ & $1,0 \mathrm{~g}$ \\
\hline $\mathrm{J} 20$ & $P e-a$ & 1,98 abcdef & $1,72 \mathrm{a}$ & $1,38 \mathrm{ab}$ & $3,02 \mathrm{abc}$ & $1,8 \mathrm{ab}$ & 2,88 abcdef \\
\hline M17 & $P e-a$ & $2,22 \mathrm{abcdef}$ & $1,28 \mathrm{a}$ & $1,32 \mathrm{ab}$ & $2,92 a b c$ & $1,88 \mathrm{ab}$ & 2,98 abcdef \\
\hline
\end{tabular}

${ }^{1} \mathrm{~Pa}=$ P. alata; $P c=P$. cincinnata; $P e-r=P$. edulis roxo; $P e-a=P$. edulis amarelo, e $P s=P$. setacea. Médias seguidas por mesma letra na coluna não diferem entre si, pelo teste de Kruskal-Wallis, a $5 \%$ de probabilidade. 


\section{CONCLUSÕES}

1-A escala de notas proposta permite a identificação da variabilidade dos acessos de maracujazeiro para resistência a doenças foliares e de frutos, de forma rápida e discriminatória.

2-De modo geral, acessos de maracujazeiro-amarelo e roxo são mais suscetíveis à virose do endurecimento dos frutos, antracnose e verrugose, enquanto espécies silvestres de Passiflora, a exemplo de $P$. setacea, possuem resistência a uma ampla gama de doenças.

3-A existência de níveis variados de resistência à virose, antracnose e verrugose em $P$. edulis (maracujazeiro-amarelo e roxo) abre perspectivas para rápida introdução destes genes em variedades comerciais, de forma a evitar o uso de espécies silvestres que aumentam o tempo de obtenção de variedades com frutos de qualidade para atendimento das exigências do mercado.

\section{AGRADECIMENTOS}

Os autores agradecem ao CNPq, FAPESB e CAPES, pelo auxílio financeiro. T.L.S. agradece à CAPES e E.J.O., ao CNPq, pela concessão das bolsas.

\section{REFERÊNCIAS}

ABREU, S. P. M. Desempenho agronômico, características físico-químicas e reação à doença em genótipos de maracujazeiro-azedo cultivados no Distrito Federal. 2006. 129 f. Dissertação (Mestrado em Agronomia) - Faculdade de Agronomia e Medicina Veterinária, Universidade de Brasília, Brasília, 2006.

AQUINO, L. A.; BERGER P. G.; RODRIGUES, F. A.; ZAMBOLIM, L.; HERNANDEZ, J. F. R.; MIRANDA, L. M. Elaboração e validação de escala diagramática para quantificação da mancha de ramularia do algodoeiro. Summa Phytopathologica, Botucatu, v.34, n.4, p.361-363, 2008.

BOUZA, R. B. Reação em progênies de maracujáazedo à antracnose, septoriose, cladosporiose e bacteriose em condições de campo e casa de vegetação. 2009. 160 f. Dissertação (Mestrado em Fitopatologia) - Universidade de Brasília, Brasília, 2009.
CHAGAS, H. A.; BASSETO, M. A.; ROSA, D. D.; ZANOTTO, M. D.; FURTADO, E. L. Escala diagramática para avaliação de mofo cinzento (Amphobotrys ricini) da mamoneira (Ricinus communis L.). Summa Phytopathologica, Botucatu, v. 36, n. 2, p. 164-167, 2010.

FISCHER, I. H.; ALVES, S. A. M.; ALMEIDA, A. M.; ARRUDA, M. C.; BERTANI, R. M. A.; GARCIA, M. J. M. Elaboração e validação de escala diagramática para quantificação da severidade da antracnose em frutos de maracujá amarelo. Summa Phytopathologica, Botucatu, v. 35, n. 3 p. 226-228, 2009.

GONÇALVES, I. M. P. Produtividade e reação de progênies de maracujazeiro azedo a doenças em campo e casa de vegetação. 2011. $121 \mathrm{f}$. Dissertação (Mestrado em Agronomia) - Faculdade de Agronomia e Medicina Veterinária, Universidade de Brasília, Brasília, 2011.

IBGE. Banco de dados agregados. Sistema IBGE de Recuperação Automática - SIDRA. Disponível em: $<$ http://www.ibge.gov.br>. Acesso em: 28 nov. 2010.

JUNQUEIRA, N. T. V.; ANJOS, J. R. N. dos; SILVA, A. P. O.; CHAVES, R. C.; GOMES, A. C. Reação as doenças e produtividade de onze cultivares de maracujá-azedo cultivados sem agrotóxicos. Pesquisa Agropecuária Brasileira, Brasília, v. 38, n. 8, p.1005-1010, 2003.

JUNQUEIRA, N. T. V.; BRAGA, M. F.; FALEIRO, F. G.; PEIXOTO, J. R.; BERNACCI, L. C. Potencial de espécies silvestres de maracujazeiro como fonte de resistência a doenças. In: FALEIRO, F. G.; JUNQUEIRA, N. T. V.; BRAGA, M. F. Maracujá: germoplasma e melhoramento genético. Planaltina: Embrapa Cerrados, 2005. p. 81-108.

LARANJEIRA, F. F. Problemas e perspectivas da avaliação de doenças como suporte ao melhoramento do maracujazeiro. In: FALEIRO, F. G.; JUNQUEIRA, N. T.V.; BRAGA, M. F. Maracujá: germoplasma e melhoramento genético. Planaltina: Embrapa Cerrados, 2005. p.161-184.

LEÃO, R. M. K.; PEIXOTO, J. R.; JUNQUEIRA, N. T. V.; REZENDE, R. O.; MATTOS, J. K. A.; MELO, B. Reação de progênies de maracujazeiro-azedo ao vírus do endurecimento do fruto (Cowpea aphid-borne mosaic vírus - CABMV) em casa de vegetação. Bioescience Journal, Uberlândia, v. 22, n. 2, p. 87-92, 2006. 
LENZ, G.; COSTA, I. D.; BALARDIN, R. S.; MARQUES, L. N.; ARRUÉ, A.; STEFANELO, M. S.; ZEMOLIN, C. R. Elaboração e validação de escala diagramática para quantificação da mancha de isariopsis da videira. Ciência Rural, Santa Maria, v.39, n.8, p. 2301-2308, 2009.

MARTINS, I. Reação de progênies de maracujazeiro-amarelo ao Colletotrichum gloeosporioides e biocontrole da antracnose com Trichoderma spp. 2006. 137 f. Dissertação (Mestrado em Agronomia) - Faculdade de Agronomia e Medicina Veterinária, Universidade de Brasília, Brasília, 2006.

MELETTI, L. M. Avanços na fruticultura tropical no Brasil. Revista Brasileira de Fruticultura, Jaboticabal. v. 33. n.1, edição especial. p. 73 - 91. 2011.

MIRANDA, H. A. Incidência e severidade Xanthomonas oxonopodis pv. Passiflorae, Colletotrichum gloeosporioides, Septoria passiflorae, Cladosporim herbarum e Passion fruit woodiness vírus em genótipos de maracujazeiro azedo cultivados no Distrito Federal. 2004. 87 f. Dissertação (Mestrado em Agronomia) - Faculdade de Agronomia e Medicina Veterinária Universidade de Brasília, Brasília, 2004.
NASCIMENTO, A.S.; SOUZA, A.R.R.; ALFENAS, P.F.; ANDRADE, G.P.; CARVALHO, M.G.; PIORIBEIRO, G.; ZERBINI, F.M. Análise filogenética de potyvírus causando endurecimento dos frutos do maracujazeiro no Nordeste do Brasil. Fitopatologia Brasileira, Brasília, v.29, p.378-383, 2004.

NOVAES, Q. S.; REZENDE, J. A. M. Possível aplicação do DAS-ELISA indireto na seleção de maracujazeiro tolerante ao "Passionfruit Woodiness Virus”. Fitopatologia Brasileira, Brasília, v. 24, n.1, p. 76-79, 1999.

DEVELOPMENT CORE TEAM. R: A language and environment for statistical computing., Vienna: R Foundation for Statistical Computing, 2006. Disponível em: <http://www.R-project.org>. Acesso em: fev. 2010.

VAN REGENMORTEL, M. H. V.; FAUQUET, C. M.; BISHOP, D. H. L.; CARSTENS, E.; ESTES, M. K.; LEMON, S. M.; MANILOFF, J.; MAYO, M. A.; MCGEOCH, D. J.; PRINGLE,C. R.; WICKNER, R. B. (Ed.). Virus taxonomy: seventh report of the international committee on taxonomy of viruses. San Diego: Academic Press, 2000. 1162 p. 